\title{
Journal of Food Nutrition and Population Health
}

ISSN 2577-0586

The journal has been started in the year 2017 and it released its first volume in the same year. Till now, the journal has released 3 volumes by the end of 2019 and is successfully running its 4th Volume.

The Journal is an open access publication that features scientific works of considerable significance and impact in all fields of:

\section{Nutrition}

\section{Phytonutrients}

Food science

\section{Bioavailability of nutrients}

\section{Human nutrition}

Health sciences

\section{Clinical nutrition}

\section{Micronutrients}

Public health

Trace elements and Nutraceuticals.

It is a boon for researchers and students who wish to be kept abreast of the latest advancements in these fields, it would help them build on the current know-how. Business people, policy makers, journalists, and practitioners can also benefit from the works published in the journal.

\section{Some of the articles released in $\mathbf{2 0 1 9}$ are as follows:}

1. Phenolic Compounds Identification and Antioxidant Activity in Bananas of $A A B$ and $A B B$ Genomes Grown in Uganda

2. Food Poisoning of the Infantile Group, Microbiological Standpoint

The journal has released the conference details relating to the journal in 2019. In the same way, the Journal expects to cover all the above classification topics for the year 2020 along with the present research in this field along with the current situation prevailing in globally i.e., COVID19. 


\section{Social media/digital marketing:}

The journal always was in contact with the scientific group of the world through its mails, social media networks and its digital platforms. Some of the best ways to be in contact with the audiences' are:

1. Twitter postings: Regularly posting the articles, trends, updates of the journal. They can be visible at @Alessan61730774.

2. Posting Google Analytics data in the website.

3. Using Linkedln and Facebook for regular updates.

4. Regularly being in contact not only through mails but also through Whats App.

The complete details about the journal can be seen at: https://www.imedpub.com/foodnutrition- and-population-health/and for contacting us, mail us or WhatsApp us.

So, as an Editor, I invite all the extended dignitaries in this field to submit their articles for bringing this research/expertise to the global scientific community.

Regards

Jin Xian Chu 